\title{
Effects of school type and gender on student's self-concept and mathematics achievement
}

\author{
Mavis Okyere \\ Faculty of Education, Catholic University College of Ghana, Fiapre-Sunyani, Ghana. \\ Email: mavisokyere020@gmail.com; mavis.okyere@cucg.edu.gh.
}

Copyright @ 2019 Okyere. This article remains permanently open access under the terms of the Creative Commons Attribution License 4.0, which permits unrestricted use, distribution, and reproduction in any medium, provided the original work is properly cited.

Received 18th February, 2019; Accepted 22nd March, 2019

\begin{abstract}
The attention of mathematics educators has been focused on the role self-concept plays in students' achievement for some time now. A great number of studies shows evidence of a relationship between self-concept and mathematics achievement. Some other studies considered gender differences in self-concept and mathematics achievement. This study was designed to extend the discussions on self-concept and mathematics achievement to include the interaction effect of school type and gender on self-concept and mathematics achievement. The study involved 119 students selected from three different types of school within a district. The schools were selected using stratified random sampling whiles the students were conveniently sampled. A self-concept questionnaire and mathematics achievement test were the two instruments used to gather data for the study. The instruments had reliabilities of 0.72 and 0.68 respectively. The result of the study revealed that both gender and school type have a significant effect on students' self-concept and mathematics achievement, however, the effect of school type was found to be greater than that of gender. The study found no significant interaction effect of school type and gender on self-concept and mathematics achievement. The findings of the study were discussed in relation to previous findings. It was recommended that the characteristics of the schools need to be studied in order to determine the school variables that impact mathematics self-concept and achievement.
\end{abstract}

Keywords: Achievement, gender, interaction, private school, public school, self-concept, school type.

\section{INTRODUCTION}

Mathematics is an enabling discipline for science, technology, engineering, as well as economics and their related fields. No doubt, it is regarded as an important gateway to adult life and occupational opportunities for many (Forgasz and Leder, 2017). It is a compulsory school subject for basic and secondary levels in many parts of the world because of the important role it plays in the socioeconomic development of a nation (Noureen and Sheikh, 2016) as well as its attributes to rural development. As such, in Ghana, it is compulsory from primary through senior high school and serves as a requirement to gaining admission into institutions of higher learning. It is believed that adequate knowledge in mathematics serves as a basis for students' successful completion of their program of study. For this reason, most institutions of higher learning such as the universities insist students take mathematics course in their early stages of their study. Example, in Catholic University College of Ghana, it is compulsory for every first-year student of the undergradduate level to take CES 105: Introduction to Mathematics. This is designed to provide students with the knowledge base required to be successful in other courses.

Based on this relevance of the subject as mentioned in the preceding paragraph, many studies have sought to identify factors that impact student learning of the subject. Among the factors identified to influence the learning of the subject are: student-related factors; gender, attitude, selfefficacy, self-concept (Awuah et al., 2011; Marsh and Craven, 2006; Mendick, 2005; Noureen and Sheikh, 2016), school-related factors; school climate, classroom engagement, assessment, school poverty etc, (Mohammadpour et al., 2015; Neuenschwander et al., 
2017; Winnaar et al., 2015), home-related factors; socioeconomic status, time spent on household chores and on studies etc (Lay and Chandrasegaran, 2016; Mohammadpour et al., 2015; Ntim and Okyere, 2014).

However, researchers have not considered how these identified factors interact to affect students' performance in mathematics. This study, therefore, sought to look into how two of the identified variables interact to affect selfconcept and mathematics achievement. This study investigated the extent to which gender and school type interact to affect students' mathematics self-concept and their performance in mathematics. The underlining assumption for this study is that gender and school type combine to influence student's self-concept and mathematics achievement. Buschor et al. (2014) (as cited in Forgasz and Leder, 2017) notes the interplay between individual aspects and the social context in contributing to the gender disparities in students' mathematics selfconcept. It is based on this that this study investigated how the school as a social institution contributes to gender disparities in mathematics self-concept and achievement. This study assumes that gender interact with the school contexts to produce effects on mathematics self-concept and mathematics achievement. Results from this study may pave the way toward rethinking and reassessing of the priorities for investment in schools; school resources, and school management in Ghana in particular and Africa in general.

In this study, self-concept is defined as students' beliefs about their capabilities to produce expected levels of performance in mathematics. Self-concept beliefs determine how people feel, think, motivate themselves and behave (Bandura, 1994). The mathematics performance of students is defined as the score they obtained in an endof-year mathematics examination.

\section{Student's gender and self-concept in mathematics}

There are a number of studies that have focused on students' self-concept and attitude towards mathematics. Some of these studies revealed that female students have less positive attitudes toward mathematics and have less interest in mathematics-related careers than male students (Baram-Tsabari and Yarden, 2011; Hyde and Mertz, 2009; Mendick, 2005). Furthermore, girls feel higher anxiety and have lower self-assessment in sciencerelated subjects (Britner, 2008).

Pekun and Zimgibl (2004) (as cited by Preckel et al., 2008) analysis of the PISA 2003 assessment results of 15-yearold students (students in the last stages of secondary education) in countries of the Organisation for Economic Co-operation and Development (OECD) found effect sizes between 0.14 and 0.72 for gender difference in academic self-concept in mathematics, in favor of boys. Thus, indicating boys have higher self-perceptions of their math abilities than do girls.

This study examines gender differences in self-concept and achievement in mathematics at the Junior high school level. This study is important because its findings will reveal how nature of school (school type) contribute to gender disparities in mathematics self-concept and achievement. The study was conducted at the junior high school level because the researcher believes that gender gaps in mathematics achievement and self-concept starts at the lower levels of education.

\section{Student's gender and achievement in mathematics}

Evidence shows that mathematics has been regarded as a male domain for a long time. Example, Henrion (1997) (as cited in Forgasz and Leder, 2017) observed that throughout history, it is belief that women are no good in mathematics. It was argued that women's brains were too small, later that mathematics would compromise their reproductive capacities, still later that their hormones were not compatible with mathematical development. This belief system still persists in many parts of the world especially in Africa where the male is regarded as superior to the female.

There are many empirical studies on the gender achievement gap for individual countries as well as other cross-national comparisons. Considerable evidence from many countries shows that boys have an advantage over girls in mathematics and science while others find no gender achievement differences. In some other instances, girls outperform boys in some countries (Lai, 2010; Hyde and Mertz 2009).

Forgasz and Leder (2017) mentioned that mathematical literacy which was a particular focus in the PISA surveys administered in 2003 and 2012 revealed that, at both exams, gender differences were found in the mean performance scores of the two groups overall and by country; more often, the difference favoured boys. They continued to explain that in 2003 , the mean performance of boys exceeded that of girls in all but one of the 29 participating OECD countries; PISA 2012 data for these same countries still revealed differences in favour of males in 26 countries.

Li et al. (2017) in their study of the gender gap in mathematics and physics in Chinese middle schools found that significant gender gaps favouring male students exist in High School Entrance Exam (HSEE) mathematics and physics scores and the gender gap is enlarged when the urban-rural residency is taken into account. In this study, the gender gap in self-concept and achievement in relation to school type was investigated using schools within the same vicinity.

\section{School verses self-concept and achievement in mathematics}

Many writers suggest that the school is one of the settings for cultivating social justification of cognitive abilities during 
the formative periods of children's lives. In schools, students' knowledge and thinking skills are frequently tested, evaluated, and compared. As children master cognitive skills, they develop a growing sense of their intellectual worth. Bandura (1994) indicated that many social factors, apart from the formal instruction, such as peer modeling of cognitive skills, social comparison with the performances of other students, motivational enhancement through goals and positive incentives, and teachers' interpretations of children's successes and failures in ways that reflect favourably or unfavourably on their abilities also affect children's judgments of their intellectual abilities. Many studies on schools are based on models of school effectiveness and school quality which are based on theoretical approaches and empirical findings.

Howie and Plomps (2003) analysis of South African TIMSS 1995 data using multilevel models proved that about 55 per cent of the variation in students' achievement levels in mathematics can be explained by the differences in the quality of the schools they attend. Their analysis also showed that students' proficiency in the English language is an important determinant of their success in learning mathematics. Thus, the language of an examination, as well as, the nature of school attended are contributing factors to students' success or failure in an examination. Students' have better chances of being successful in an examination that is in the language they are fluent in, or if the language of the examination is their mother tongue.

Awofala (2017) also in his study of senior secondary school students' mathematical proficiency as related to gender and performance in mathematics found that senior secondary school students from the elitist schools showed a high level of mathematical proficiency. Awofala's findings also confirm how school quality significantly affect students learning. Other studies also confirm the significant impact the school has on students' achievements. Winnaar et al. (2015) analysing TIMSS 2011 data for South Africa indicated that differences in schools account for about $62 \%$ of the variation in students' achievement levels in mathematics. Students are more successful when they attend schools that are adequately resourced, have teachers that are satisfied with their working conditions and that are specialised in the field of mathematics.

Lay and Chandrasegaran (2016) in their study of eighth graders performance in science also found that students in schools that were affected by shortages of science resources had lower achievement than students in schools that were not affected by shortages. They also found that having the language of the examination as your first language has a significant positive effect on performance. This study investigated if being in certain kind of school matters. The study investigated how being in a private or public basic school affects students' mathematics selfconcept and achievement.

\section{Students' self-concept and mathematics achievement}

In the academic domain, students' self-concepts are primarily their self-perceptions about themselves in academic work and these perceptions influence academic behaviours and educational outcomes (Yeung et al., 2013). It is believed that self-perceptions and beliefs do impact educational outcomes for students. Many studies on academic self-concept have proven it to be an important educational outcome in itself, and also an important factor that contributes to other valued educational outcomes (Craven et al., 2003). Students' academic achievement has been found to be closely associated with their academic self-concept (Awuah et al., 2011; Marsh and Craven, 2006).

Craven and Yeung (2008) (as cited in Yeung et al., 2013) are of the view that, if self-concept is enhanced in appropriate way, applying the principle of domain specificity, it will be able to enhance self-concept in a specific domain so as to positively influence educational outcomes within that specific domain. Ismail and Anwang (2009) found that students who had a high positive selfconcept about mathematics also achieved high in mathematics.

The results of an analysis of TIMSS 2011 data for South Africa students show that the attitude of the students toward mathematics has an impact on their performance (Winnaar et al., 2015). However, other studies revealed students' self-concept had no effect on mathematics achievement. Kanafiah and Jumadi (2013) found that student's attitude and interest are insignificant factors in contributing to the lower results in Mathematics.

Some research results also show negative relationships between self-concept and mathematics achievement. For example, Kifer (2002) presented findings from TIMSS that suggested a negative relationship between self-concept and mathematics and science achievement, observing that students in many of the highest performing countries in terms of achievement had some of the lowest overall beliefs in their ability to perform. These contradicting findings suggest that there are other factors that might influence self-concept or mathematics achievement that needs to be investigated. For this reason, this study sought to find the interaction of school type and gender on selfconcept and mathematics achievement. The findings of this study will add to body of knowledge on students' mathematics self-concept and achievement.

\section{Basic schools in Ghana}

The basic schools in Ghana are mainly distinguished into two main types by the ministry of education. They a distinguished into the 'private' and the 'public' schools. The private schools are non-government schools managed by private individuals or groups and the public schools are 
managed by the government. However, both the private and the public are under the supervision of the Ghana Education Service of the Ministry of Education (Ministry of Education, 2017).

The public schools in Ghana can again be characterized into two types; those managed by religious bodies under the supervision of Ghana Education Service, also termed as faith-based or mission schools, and those managed solely by local appointees under the Ghana Education Service (referred to in this study as local authority schools). These three types of basic schools (The private, the mission and the local authority) follow the same curriculum designed by the Curriculum Research and Development Division (CRDD) of the Ministry of Education and as such, they take a common end of programme examination called the Basic Education Certificate Examination. For this reason, it is appropriate if researchers conduct studies that compare these types of schools or the students from these schools.

A Large-scale study on school effectiveness conducted in Ghana by United States Agency for International Development (USAID) in 2005 showed that school level factors such as English language ability of students, availability of textbooks, and teachers' qualifications in education significantly contribute to students' achievement.

Ampiah (2008) in a study into the provision of quality of basic education in Ghana found that the major differences between private and public schools were better English language usage of the pupils and greater availability and ownership of textbooks in the private schools compared to urban and rural public schools in that order. This study intends to investigate how the different school types (private school, public mission school and public local authority school) influence students' self-concept and achievement in mathematics. The researcher selected these three types of schools for the study because they differ in (a) their daily usage of the English language for communication at school - those in the private school use the language more and as early as nursery and are fluent than those in the public schools, and the public mission school emphasise the use of the English language especially for instruction at the junior high school level than the public local authority school. (b) access to reading and other teaching-learning materials is greater in the private, followed by the mission, and then the local authority school in that order. (c) school environment including infrastructure is better for the private as compared to the mission and the local authority school in that order.

The main purpose of this study was to investigate whether school type and gender interact to influence students' mathematics self-concept and achievement. The following research questions were used to guide the study:

1. What is the effect of gender on students' self-concept and achievement in mathematics?

2. What is the effect of school type on students' self- concept and achievement in mathematics?

3. What is the interaction effect of gender and school type on students' self-concept and achievement in mathematics?

\section{METHODOLOGY}

The descriptive survey design was employed in this study. According to Cohen et al. (2007), surveys are used to gather data at a particular point in time with the intention of describing the nature of existing conditions or determining the relationships that exist between specific events. In this study, data was gathered about students' self-concept and achievement in order to describe these variables in relation to student's gender and the type of school attended.

Within the school district where the study took place, there were 13 Junior High Schools. The schools were grouped into private, mission, and local authority. There were 5 mission schools, 5 private schools and 3 local authority schools. Stratified random sampling was used to select one school each from these three categories of schools- Private, public mission and local authority. The participants for the study were selected from the grade 8 (form two) classes of the selected schools because the grade 9 (form three) students had already completed their Basic Education Certificate Examinations (BECE) and were no more in school at the time of the study. The grade 7 (form one) students were not involved in the study because the researcher learnt from the headteachers that most of them had not spent more than a year in the schools. Most of the grade 7 students were admitted in their respective schools the same year the study took place. So, in the researcher's view, most of the grade 7 students had not stayed in the schools long enough for the schools to have much impact on them, hence grade 8 students were due appropriate for the study. Intact grade8 classes were involved. There were two grade- 8 classes from the private school and one class each from the other two schools. Two students of the mission school and five students of the private school were not involved in the study because they did not give their consent to participate. In all, the study involved 119 students selected from the three Junior High Schools. There were 40 students from the private school, 43 from the mission school and 36 from the local authority school. The sample consisted of 59 males and 60 females. Ages between 14 and 15 years.

\section{Instruments}

Two instruments were used to collect data: Self-concept questionnaire and an achievement test. The self-concept questionnaire had 12 items. Examples of the items are; "I think I can handle more difficult mathematics", "I am not 
the type to do well in mathematics". All the items were measured on a five-point scale. The questionnaire items were adapted from the students' questionnaire developed by International Association for the Evaluation of Educational Achievement (IEA, 2007) and used in Trends in International Mathematics and Science Study (TIMSS) 2007. The reliability coefficient of the items was estimated using the Cronbach alpha estimates. The Cronbach alpha for the self-concept questionnaire was calculated to be 0.72 , indicating a high reliability. According to Pallant (2013), reliability coefficient of 0.7 and above is considered to be high.

The achievement test is the annual mathematics achievement test (end of the academic year test) consisting of 50 multiple-choice items covering the mathematics content of the grade-8 mathematics curriculum of Ghana. The test was constructed and administered to all grade eight junior high school students in the district at the end-of the year by the district education office of the Ghana Education Service. Prior to the administration of the instruments, the researcher visited the schools to explain the purpose of the study to the school authorities and to seek their permission to conduct the study in their schools. The purpose of the study was then explained to the students and the researcher sought the students' consent to participate in the study. With permission from the school authorities and consent from the 119 students, the questionnaire was administered to the students through the help of four undergraduate students and the mathematics teachers of the respective schools.

The questionnaire was administered to the students in the morning before the test was administered to them. The students scores on the test were obtained from the schools after they were scored by the mathematics teachers. The reliability of the multiple-choice test items was estimated using the KR-20 reliability estimate because the items were not of the same difficulty level. The reliability was found to be 0.68 which could be considered good enough because it is almost 0.7 (Pallant, 2013).

\section{Data analysis}

The students' responses to the questionnaire items were coded such that higher scores reflected more favourable responses. Positively worded items or items measuring positive constructs were coded as follows; 1-SD, 2-D, 3-U, 4-A, 5-SA. Hence the negatively worded items or items measuring negative constructs were reverse coded. Responses to the items were summed together to represent a student's total score on self-concept. The total score on the questionnaire has a range between 12 to 60 . The multiple-choice (achievement test) items were scored right or wrong. Each right answer attracts one mark so the highest score on the items was 50 and the lowest was 0.

The data gathered from the questionnaire and the achievement test were analysed quantitatively using inferential statistics. The depend variables (DV) were self- concepts and mathematics score, and the independent variables were gender and school-type. To calculate group differences in self-concept and mathematics achievement, multivariate analysis of variance MANOVA was performed using the type of school and student' gender as fixed factors and the scores on self-concept and the end-of -year mathematics test as dependent variables. Two-tailed significance tests at $\alpha=0.05$ were used for the analysis.

Independent and normality assumptions for MANOVA test were assumed to hold because of the sampling technique used and the sample size involved. Data were gathered from students selected from three separate schools and the sample size was large $(n=119)$ and group sizes were similar, there were no missing data. Other assumptions for MANOVA were tested.

There was a linear relationship between the two dependent variables (DVs). The Mahalanobis distance was used to check outliers, the maximum value was found to be 11.714 which does not exceed the criteria of 13.82 for two DVs and 16.27 for three DVs. Sample variances for the groups were compared, no DV had the ratio of largest to smallest variance approaching 10:1 (Tabachnick and Fidell, 2018). One group failed to meet the normality assumption on one of the DVs, however, all the MANOVA test statistics are relatively robust to violation of multivariate normality (Field, 2005).

\section{RESULTS}

The multivariate analysis of variance, MANOVA test was used for all the three research questions. Research question one was to find out the effect of gender on students' self-concept and achievement in mathematics. The result of the MANOVA test as in Table 1 shows that student's gender significantly affects student's selfconcept and mathematics achievement. Wilks' $\lambda=$ $0.908, F(2,112)=5.466, p<0.05, \eta^{2}=0.092$. A follow- up univariate analysis of variance shown in Table 2 revealed a significant gender difference in self-concept $[F(1,118)=$ 7.121, $\left.p=0.009, \eta^{2}=.06\right]$ and mathematics achievement $\left.\left[F(1,118)=5.696, p=0.019, \eta^{2}=0.05\right]\right]$. The descriptive statistics as in Table 4 shows that male students $[\mathrm{M}=$ $42.44, \mathrm{SD}=3.838$ and $\mathrm{M}=41.05, \mathrm{SD}=0.320]$ performed relatively higher than female students $[M=40.13, S D=$ 3.959 and $\mathrm{M}=39.63, \mathrm{SD}=3.979$ ] on both self-concept and the mathematics achievement respectively. The standard deviations show that the scores of the female students on both the self-concept and the exam dispersed from their means than those of the male students. The effect sizes of gender on self-confidence and gender on mathematics achievement were calculated (the square root of the eta squares) to be 0.25 and 0.22 respectively indicating medium effects of gender on the two variables (Pierce et al., 2004).

Research question two: What is the effect of school type on students' self-concept and achievement in mathematics? was answered by the same MANOVA test. 
Table 1. MANOVA test for the effects and interaction of gender and school type on students' self-concept and mathematics achievement.

\begin{tabular}{llccccc}
\hline Effect & & Value & F & Hypothesis df & Error df & Sig. \\
\hline Intercept & Wilks' Lambda & 0.005 & $10879.228^{\mathrm{b}}$ & 2.000 & 112.000 & 0.000 \\
School & Wilks' Lambda & 0.597 & $16.461^{\mathrm{b}}$ & 4.000 & 224.000 & 0.000 \\
Gender & Wilks' Lambda & 0.908 & $5.655^{\mathrm{b}}$ & 2.000 & 112.000 & 0.005 \\
School * gender & Wilks' Lambda & 0.964 & $1.038^{\mathrm{b}}$ & 4.000 & 224.000 & 0.388 \\
\hline
\end{tabular}

The * indicate the interaction between school and gender.

Table 2. Univariate analysis of variance by gender.

\begin{tabular}{llccccc}
\hline Parameters & & Sum of Squares & df & Mean Square & F & Sig. \\
\hline \multirow{3}{*}{ Self-concept } & Between Groups & 151.887 & 1 & 151.887 & 7.121 & 0.009 \\
& Within Groups & 2495.390 & 117 & 21.328 & & \\
& Total & 2647.277 & 118 & & & \\
& & & & & & \\
\multirow{2}{*}{ Achievement } & Between Groups & 105.388 & 1 & 105.388 & 5.696 & 0.019 \\
& Within Groups & 2164.579 & 117 & 18.501 & & \\
& Total & 2269.966 & 118 & & & \\
\hline
\end{tabular}

Table 3. Univariate analysis of variance by school type.

\begin{tabular}{llccccc}
\hline Parameters & & Sum of Squares & df & Mean Square & F & Sig. \\
\hline \multirow{3}{*}{ Self-concept } & Between Groups & 912.201 & 2 & 456.100 & 30.493 & 0.000 \\
& Within Groups & 1735.077 & 116 & 14.958 & & \\
& Total & 2647.277 & 118 & & & \\
& & & & & & \\
Achievement & Between Groups & 546.898 & 2 & 273.449 & 18.409 & 0.000 \\
& Within Groups & 1723.069 & 116 & 14.854 & & \\
& Total & 2269.966 & 118 & & & \\
\hline
\end{tabular}

Table 4. Mean (SD) for self-concept and mathematics achievement by gender and school type.

\begin{tabular}{lccccc}
\hline \multirow{2}{*}{ Parameters } & \multicolumn{2}{c}{ Gender } & \multicolumn{3}{c}{ School Type } \\
\cline { 2 - 5 } & Males & Females & Private & Mission & Local Authority \\
\hline Self-concept & $42.44(3.838)$ & $40.13(3.959)$ & $44.63(2.815)$ & $41.47(3.501)$ & $38.00(3.481)$ \\
Achievement & $41.05(0.320)$ & $39.63(3.979)$ & $42.45(1.880)$ & $40.49(3.120)$ & $37.81(3.328)$ \\
\hline
\end{tabular}

The test result as in Table 1 revealed a significant effect of school type on self-concept and achievement, Wilks' $\lambda=$ $0.507, F(4,224)=16.461, p<0.05, \eta^{2}=0.227$. Again, a univariate analysis of variance by school type, presented in Table 3 shows a significant difference in self-concept. $\left[F(2,118)=30.493, p=0.000, \eta^{2}=0.354\right]$ and mathematics achievement $\left[F(2,118)=18.409, \vec{\leftrightarrow} p=0.000, \eta^{2}=\right.$ $0.294]$ among the three school types. The private school outperformed the mission and the local authority school, and the mission school also outperformed the local authority as shown in Table 4. The private school showed a higher positive self-concept and also performed higher on the achievement test respectively $[\mathrm{M}=44.63, \mathrm{SD}=$ 2.815 and $\mathrm{M}=42.45, \mathrm{SD}=1.880$ ] than the mission and the local authority school. The mission school also scored higher on the two variables $[\mathrm{M}=41.47, \mathrm{SD}=3.501$ and $\mathrm{M}$ $=40.49, \mathrm{SD}=3.120]$ than the local authority school $[\mathrm{M}=$ $38.00, S D=3.481$ and $M=37.81, S D=3.328]$. School type had 0.595 and 0.542 effects respectively on selfconcept and mathematics achievement. Thus, school type has a very large effect on students' self-concept and mathematics achievement (Pierce et al., 2004). 
Research question three was to find out if there is an interaction effect of gender and school type on students' self-concept and mathematics achievement. The MANOVA results as shown in Table 1 indicate no significant interaction effect between student's gender and school type, Wilks' $\lambda=0.975, F(4,224)=0.727, p=0.574$. This indicates that the effect of school type on self-concept and mathematics achievement is similar for both male and female students.

\section{DISCUSSIONS}

Testing the effects of student's gender and school type on self-concept and mathematics achievement answered research questions one and two. Similar to other earlier findings (Li et al., 2017; Baram-Tsabari, 2011; Britner, 2008), the results of this study revealed that students gender had effects on student's self-concept and student mathematics achievement. The male students tend to have a higher estimation of their self-concept and achieved higher in the mathematics achievement test than the female students. The effect sizes of the student's gender effects on self-concept and mathematics achievement calculated from the eta squares were found to be medium. It is found that gender explains $25 \%$ of variation in students' self-concept and $22 \%$ of variation in mathematics achievement. This finding is also consistent with the findings of Pekun and Zimgibl (2004) (as cited in Preckel et al., 2008) who in the analysis of the PISA 2003 assessment results of 15-year-old student in countries of the Organisation for Economic Co-operation and Development (OECD) found effect sizes between 0.14 and 0.72 for gender difference in academic self-concept in mathematics in favour of boys. With respect to gender and mathematics achievement, the finding agrees with the findings of Li et al. (2017) who found that significant gender gaps in mathematics achievement favouring male students exist in Chinese High Schools.

Also, the study revealed that the type of school attended has a significant effect on junior high school students' selfconcept and mathematics achievement. Students in the private school scored highest on the mathematics test and showed the highest level of self-confidence. Those students from the mission school also scored higher in both the self-confidence and the mathematics test than the students from the local authority school. This finding is also consistent with previous findings like that of Howie and Plomps (2003), Winnar et al. (2015) and Awofala (2017). The effect sizes of school type on self-confidence and mathematics achievement were found to be large $(0.595$ and 0.542 respectively). That is, the type of school attended has greater and significant effect on students' self-concept and mathematics achievement than gender has. School type explains $59.5 \%$ of variation in students' self-concept and $54.2 \%$ of variation in mathematics achievement. The value of effect size obtained in this study for school effect on mathematics achievement is comparable to that obtained by Winnaar et al. (2015) and that of Howie and Plomps (2003). Howie and Plomps (2003) in analysis of South African TIMSS 1995 data using multilevel models found that about 55 per cent of the variation in students' achievement levels in mathematics can be explained by the differences in the quality of the schools they attend. And Winnaar et al. (2015) in their analysis of TIMSS 2011 data for South Africa also found that $62 \%$ of the variation in students' achievement levels in mathematics were as a result of school related factors.

The interaction effect which answers research question three was found to be non-significant. That is, there is no interaction effect between school type and gender on students' self-concept and mathematics achievement. School type or characteristic of a school has similar effects on both males and females in terms of self-confidence and mathematics achievement. This founding indicates that school related factors will have similar influence on both girls and boys.

\section{Conclusion}

Gender as a factor has a low effect on student's selfconcept and mathematics achievement as compared to type of school. The result of this study implies that the school factors or school environment has large effects on students' self-concept and achievement. This indicates that learning environment may indirectly impact students' mathematics learning and mathematics self-concept. Since the private school students had a more positive selfconcept and also outperformed students from the other two school types in the achievement test, there is the need to investigate into the characteristics of the private school and model those characteristics in all other schools so as to improve students' self-concept and mathematics achievement. Since all parents cannot afford the fee for private schools, the Government of Ghana and school authorities need to consider their policies, particularly, regarding the provision of textbooks and other teachinglearning materials which are accessible to students in the private schools than students in the public schools. Also, the language policy for instruction at the basic level in the country as identified by Ampiah (2008) to be the major difference between the private and the public schools in Ghana need to be reconsidered.

\section{Recommendations}

Based on the findings and conclusion of this study, it is recommended that efforts should be made by stakeholders of education, particularly those in mathematics education to encourage students, especially, girls to develop positive self-concept towards mathematics. The study did not measure specific characteristics of the 
schools as variables, it is recommended that studies on this subject should be conducted by measuring school characteristics as variables so as to determine school variables that impact students' mathematics self-concept and achievement.

\section{CONFLICT OF INTEREST}

The author declares that there is no conflict of interest.

\section{REFERENCES}

Ampiah, G. J. (2008). An investigation of provision of quality basic education in Ghana: A case study of selected schools in the Central Region. CICE Hiroshima University. Journal of International Cooperation in Education, 11(3), 19-37.

Awofala, A. O. A. (2017). Assessing senior secondary school students' mathematical proficiency as related to gender and performance in mathematics in Nigeria. International Journal of Research in Education and Science, 3(2), 488-502.

Awuah, M., Eshun, B. A., \& Sokpe, B. Y. (2011). Impact of mathematics teachers' characteristics on female junior secondary school students' attitude and achievement in mathematics. Journal of Science and Mathematics Education. 5(1), $15-26$.

Bandura, A. (1994). Self-efficacy. In Ramachaudran, V. S. (Ed.). Encyclopedia of human behavior (Vol. 4, pp. 71-81). New York: Academic Press.

Baram-Tsabari, A., \& Yarden, A. (2011). Quantifying the gender gap in science interests. International Journal of Science and Mathematics Education, 9(3), 523-550.

Britner, S. L. (2008). Motivation in high school science students: A comparison of gender differences in life, physics and earth science classes. Journal of Research in Science Teaching, 45(8), 955-970.

Buschor, C. B., Kappler, C., Frei, A. K., \& Berweger, S. (2014). I want to be a scientist/a teacher: Students' perceptions of career decision-making in gender-typed, non-traditional areas of work. Gender and Education, 26(7), 743-758.

Cohen, L., Manion, L., \& Morrison, K. (2007). Research methods in education (6th edn). New York: Routledge.

Craven, R. G., Marsh, H. W., \& Burnett, P. (2003). Cracking the self-concept enhancement conundrum: A call and blueprint for the next generation of self-concept enhancement research. In Marsh, H. W., Craven, R. G., \& McInerney, D. M. (Eds.). International advances in self research (Vol. 1, pp. 91-126). Greenwich, CT: Information Age.

Craven, R. G., \& Yeung, A. S. (2008). International best practice in effective educational interventions: Why self-concept matters and examples from bullying, peer support, and reading research. In Mclnerney, D. M. Shawn, V. E., \& Dowson, M. (Eds.). Research on sociocultural influences on motivation and learning. Nol. 8, pp. 267-294): Teaching and learning: International best practice. Greenwich, CT: Information Age.

Field, A. (2005). Discovering statistics using SPSS (2nd edn). London: Sage publications.

Forgasz, H. L., \& Leder, G. C. (2017). Persistent gender inequities in mathematics achievement and expectations in Australia, Canada and the UK. Mathematics Education Research Journal, 29, 261-282.

Henrion, C. (1997). Women in mathematics. The addition of difference. Bloomington and Indianapolis: Indiana University Press.

Howie, S. J., \& Plomp, T. (2003). Language proficiency and contextual factors influencing secondary students' performance in mathematics in South Africa. Paper presented at the American Education Research Association Annual Meeting, Chicago, 2003. Retrieved from https://files.eric.ed.gov/fulltext/ED476656.pdf

Hyde, J. S., \& Meertz, J. E. (2009). Gender, culture, and mathematics. Proceedings of the National Academy of Sciences of the United States, 106, 8801-8807.

International Association for the Evaluation of Educational Achievement (IEA) (2007). Student Questionnaire- Grade 8. Retrieved

from https://timss.bc.edu/TIMSS2007/PDF/T07_Questionnaires_G 8.pdf.

Ismail, N. A., \& Anwang, H. (2009). Differences in mathematics achievement among eighth grade students in Malaysia. Journal of International Education Studies 2, 8-11.

Kanafiah, S., \& Jumadi, A (2013). Students' Perception Towards Mathematics: Attitudes, Interests and Lecturers' Teaching. International Symposium on Mathematical Sciences and Computing Research. 6-7th December 2013. Perak, Malaysia.

Kifer, E. A. (2002). Students' attitudes and perceptions. In Robataille, D. F. \& Beaton, A. E. (Eds.). Secondary analysis of the TIMSS data (pp. 251-275). Boston, MA: Kluwer Academic Publishers.

Lai, F. (2010). Are boys left behind? The evolution of the gender achievement gap in Beijing's middle schools. Economics of Education Review, 29(4), 383-399.

Lay, Y. F., \& Chandrasegaran, A. L. (2016). Availability of school resources and TIMSS grade 8 students' science achievement: A comparative study between Malaysia and Singapore. International Journal of Environment \& Science Education, 11(9), 3065-3080.

Li, M., Zhang, Y., \& Wang, Y. (2017). Gender gap in mathematics and physics in Chinese middle schools: A case study of a Beijing's district. Urban Review, 49, 568-584.

Marsh, H. W., \& Craven, R. G. (2006). Reciprocal effects of selfconcept and performance from a multidimensional perspective: Beyond seductive pleasure and unidimensional perspectives. Perspectives on psychological science, 1(2), 133-163.

Mendick, H. (2005). Mathematical stories: Why do more boys than girls choose to study mathematics at AS-level in England? British Journal of Sociology of Education, 26(2), 235-251.

Ministry of Education (2017). Medium Term Expenditure Framework (MTEF) for 2017-2019: 2017 budget estimates. Retrieved from www.mofep.gov.gh

Mohammadpour, E., Kalantarrashidi, A. S., \& Shekarchizadeh, A. (2015). Multilevel modeling of science achievement in the TIMSS participating countries. The Journal of Educational Research, 108, 449-464.

Neuenschwander, R., Friedman-Krauss, A., Raver, C., \& Blair, C. (2017). Teacher stress predicts child executive function: moderation by school poverty. Early Education and Development, 28(7), 880-900.

Noureen, G., \& Sheikh, I. (2016). Students mathematical problem-solving proficiency in relation to gender at grade vi. Journal of Research and Reflections in Education, 10(2), 123131.

Ntim, S., \& Okyere, M. (2014). Synergy between home environmental features, early language literacy and later reading achievement: Comparative study of urban, semi-urban 
and rural Ghanaian children. International Journal of Humanities and Social Science, 8(1), 291-300.

Pallant, J. (2013). SPSS survival manual: A step by step guide to data analysis using IBM SPSS (5th edn). England: McGrawHill.

Pekrun, R., \& Zirngibl, A. (2004). Schülermerkmale im Fach Mathematik [Student characteristics in mathematics]. In Prenzel, M., Baumert, J., Blum, W., Lehmann, R., Leutner, D., Neubrand, M., Pekrun, R., Rolff, H. G., Rost, J., \& Schiefele, U. (Eds.). PISA 2003. Der Bildungsstand der Jugendlichen in Deutschland-Ergebnisse des zweiten internationalen Vergleichs (pp. 191-210). Münster, Germany:Waxmann.

Pierce, C. A., Block, R. A., \& Aguinis, H. (2004). Cautionary note on reporting eta-squared values from multifactor ANOVA designs. Educational and Psychological Measurement, 64(6), 916-924.

Preckel, F., Goetz, T., Pekrun, R., \& Kleine, M. (2008). Gender differences in gifted and average ability students: Comparing girls' and boys' achievement, self-concept, interest, and motivation in mathematics. Gifted Child Quarterly, 52(2), 146-159.
Tabachnick, B. G., \& Fidell, L. (2018). Using multivariate statistics (6th edn). India: Pearson Education Inc.

USAID (2005). A look at learning in Ghana: The final evaluation of USAID/Ghana's Quality Improvement in Primary Schools (QUIPS) program. Accra: USAID-Ghana.

Winnaar, L. D., Frempong, G., \& Blignaut, R. (2015). Understanding school effects in South Africa using multilevel analysis: Findings from TIMSS 2011. Electronic Journal of Research in Educational Psychology, 13(1), 151-170.

Yeung, A. S., Craven, R. G., \& Ali, J. (2013). Self-concepts and educational outcomes of Indigenous Australian students in urban and rural school settings. School Psychology International 34(4), 405-427. 